\title{
Investasi Stakeholder Organisasi Seni Pertunjukan: Pengelolaan Organisasi Papermoon Puppet Theatre
}

\author{
I Putu Ardiyasa \\ Project Manager Komunitas I_Pedalangan \\ tuardiyasa@gmail.com
}

\begin{abstract}
Abstrak
Bagaimana merawat aset-aset organisasi seni pertunjukan? Sebagai organisasi yang memberdayakan "jasa", pengelolaan organisasi selau mengacu pada kehadiran penonton dukungan sponsor (funding), sehingga sangat membutuhkan hadirnya kepercayaan penonton kepada organisasi yang berkelanjutan. Organisasi seni pertunjukan cenderung tidak memperhatikan aspek pemeliharaan, karena lebih fokus pada aspek karya. Oleh sebab itu, penelitian ini mengajukan klasifikasi investasi aset terlihat (tangible asset) dan aset tidak terlihat (intangible asset) pada pengelolaan organisasi Papermon Puppet Theatre (PPT). Sembilan orang narasumber diwawancarai untuk mendapatkan informasi terkait topik penelitian tersebut. Hasilnya menunjukkan pada era digital dewasa ini, sosial media sudah menjadi gaya hidup. Bahkan hampir sejajar dengan kebutuhan primer, sehingga setiap orang tidak bisa terlepas dari keberadaan sosial media. PPT berkewajiban selalu memberikan informasi-informasi kepada stakeholder terkait kegiatan PPT.
\end{abstract}

Kata kunci: investasi, organisasi seni pertunjukan, papermoon puppet theatre

\begin{abstract}
How to take care of the assets of a performing arts organization? As an organization that empowers "services", the management of the organization always refers to the presence of audience sponsorship (funding), so it really requires the presence of audience trust in sustainable organizations. Performing arts organizations tend not to pay attention to maintenance aspects, because they are more focused on aspects of the work. Therefore, this study proposes the classification of tangible assets and intangible assets in the management of the Papermon Puppet Theater organization. Nine interviewees were interviewed to obtain information related to the research topic. The results show that in today's digital era, social media has become a lifestyle. In fact, it is almost equal to the primary needs, so that everyone cannot be separated from the existence of social media. PPT is obliged to always provide information to stakeholders regarding PPT activities.
\end{abstract}

Keywords: investment, performing arts organization, papermoon puppet theatre

\section{PENDAHULUAN}

Setiap orang dihadapkan pada berbagai pilihan dalam menentukan proporsi dana dan sumber daya untuk konsumsi saat ini dan masa datang. Menurut Tandelilin (2009:2), investasi dapat diartikan sebagai komitmen untuk menanamkan sejumlah dana pada saat 
ini dan meraih keuntungan di masa datang. Dalam konteks sederhana, seorang seniman dalang yang eksis selama lima tahun di dunia pewayangan. Sebut saja Soleh mampu menjadi dalang nasional dan mengisi berbagai festival di dalam dan luar negeri. Sejalan dengan peningkatan karier, penghasilan meningkat dari pada konsumsi saat ini. Tiba-tiba Soleh dihadapkan pada titik stagnasi yang harus memutuskan beberapa penghasilan yang akan dialokasikan untuk kebutuhan saat ini dan beberapa penghasilan dialokasikan untuk kebutuhan pada masa datang. Dengan demikian, topik ini menjadi penting untuk dikaji lebih mendalam pada ranah pengelolaan organisasi seni pertunjukan.

Bagaimana perilaku investasi pada bidang seni? Investasi dalam bidang seni secara eksplisit dapat dilihat pergerakannya pada seni rupa (lukisan). Sebagai contoh, penelitian Mei dan Moses (2002:2) yang melihat bahwa investor seni melalukan transaksi pembelian karya-karya seniman (mapan) atau membeli karya seni yang mahal. Meskipun karya seni selalu menjadi objek yang memiliki nilai moneter, namun terutama dalam empat puluh tahun terakhir, karya seni telah dilihat sebagai aset keuangan. Pembingkaian investasi ini logis bagi investor, karena menurut Coslor (2009:1), di samping terdapat manfaat estetis dari memiliki karya seni, tetapi juga menjadi bagian dari strategi diversifikasi investasi keuangan.

Menyoal investasi karya seni pertunjukan, tidak dapat dipisahkan dari keberadaan stakeholder (internal dan eksternal) organisasi. Keberadaan stakeholder internal adalah individu atau kumpulan individu (dalam hal ini seniman) yang bekerja menghadirkan karya seni. Organisasi seni pertunjukan memikirkan strategi untuk memelihara stakeholder tersebut, guna menjaga produktivitas, kontinuitas, dan kreativitas seluruh stakeholder internal. Sedangkan stakeholder eksternal adalah kumpulan individu yang memiliki ketertarikan yang sama terhadap suatu objek tertentu (penonton). Respons positif dan negatif penonton saat menonton pertunjukan menjadi hal yang wajar. Jika respons negatif lebih dominan, perlu mempertimbangkan sebab akibatnya.

Sebagai contoh, seorang wanita bernama Ria menghabiskan waktunya untuk bermain dengan media sosial (email, blog, dan Instagram) untuk berkomunikasi dengan para penggemarnya. Bahkan Ria rutin mengomunikasikan kegiatan yang dilakukan dengan memanfaatkan media daring. Karena ia merasa waktu seharian tidak cukup untuk bertemu secara langsung dengan tiga sampai empat orang, sehingga membutuhkan media untuk berkomunikasi. Seseorang akan merasa dihargai keberadaannya dengan perilaku seperti itu. Permasalahannya, apakah setiap seniman peka dan terpantik melakukan hal tersebut?

Topik yang dikedepankan pada tulisan ini terkait dengan upaya memelihara stakeholder pada organisasi seni pertunjukan. Menurut Papula dan Volna (2011:498) bahwa khusus untuk perusahaan berbasis pengetahuan (jasa), dalam mengelola sumber daya manusia (stakeholder internal), berkonsentrasi pada peningkatan kecerdasan organisasi dan mengembangkan potensi karyawan dengan mengadakan pelatihan, partisipasi, dan kolaborasi. Namun, pada kenyataannya tidak banyak organisasi seni pertunjukan yang mampu memahami pentingnya pengembangan (dalam hal ini investasi) tersebut.

Apakah berdampak pada stagnasi kreativitas? Kita dapat mengingat lebih jauh bahwa Dalang Wayang Kampung Sebelah mengalami kondisi di mana terjadi stagnasi 
kreativitas, sehingga tidak mampu menghadapi tantangan dunia pertelevisian. Wayang Kang Ching Wie di Bali sempat muncul tahun 2009, namun sekarang tidak mampu mempertahankan eksistensinya. Namun, di sisi lain, banyak pula kelompok seni atau seniman yang masih eksis, seperti Eko Supriyanto dengan Jailolonya, Didik Nini Thowok, Putu Wijaya (teater), I Wayan Nardayana (dalang), termasuk Papermoon Puppet Theater (selanjutnya disebut PPT).

Apakah kesuksesan dan kegagalan yang terjadi salah satu faktornya adalah kurangnya investasi? Melalui artikel ini, penulis membahas permasalahan tersebut dengan menyoal satu kasus pada PPT, agar memperoleh gambaran tentang pentingnya investasi pada organisasi seni pertunjukan.

\section{Pemberdayaan Keterampilan}

Memberikan bentuk apresiasi berupa pemberdayaan keterampilan anggota, responsif terhadap hal baru, dan pengembangan pengetahuan melalui program tour and riset selalu menjadi prioritas di PPT. Pemberdayaan keterampilan selalu dilakukan oleh setiap anggota secara individu maupun kolektif, baik dalam membuat boneka maupun saat latihan. Anggota PPT menguji kemampuannya dengan terus melakukan eksplorasi sesuai keterampilan masing-masing.

Sutradara bertugas membuat naskah dan menstimulasi munculnya eksplorasi terhadap objek lain, sedangkan artistik direktur membuatkan sketsa untuk boneka dan properti panggung. Selanjutnya diserahkan dan ditentukan oleh masing-masing pemain boneka pada setiap proses. Dalam rangka mengembangkan keterampilan anggota, PPT memulainya dengan hal yang sederhana. Pemanasan dimulai dengan memberdayakan kemampuan setiap individu, seperti salsa dan olah tubuh. Pola seperti ini berdampak positif terhadap kemampuan individu, dan secara kolektif meningkatkan keakraban dan kenyamanan anggota. Seperti kutipan wawancara berikut ini.

...Ya, jadi sebenarnya itu apa ya, masuk kegiatan rutin sih, tapi karena... eee... misal kita seperti olah tubuh, Mbak Ria selalu bilang "kalau dari kalian ada yang punya ide atau gagasan lain boleh lo dikembangkan sendiri dan itu bisa kalau kamu mempunyai masalah untuk melanjutkan itu bisa loh didiskusikan dengan kita...

(Wawancara Jati, 13 April 2017)

Kutipan tersebut menunjukkan bahwa pola pemberdayaan keterampilan di PPT dilakukan secara rutin dan mendapatkan respons positif dari anggota. Ketika kesempatan itu diberikan kepada anggota, dapat dikatakan bahwa mereka sedang melakukan penanaman modal secara langsung, dalam hal ini modal tak berwujud yang dapat mendukung keterampilan individunya. Model seperti ini akan merangsang respons dan daya kreatif setiap anggota terhadap hal-hal yang belum pernah dilihat atau dilakukan. 


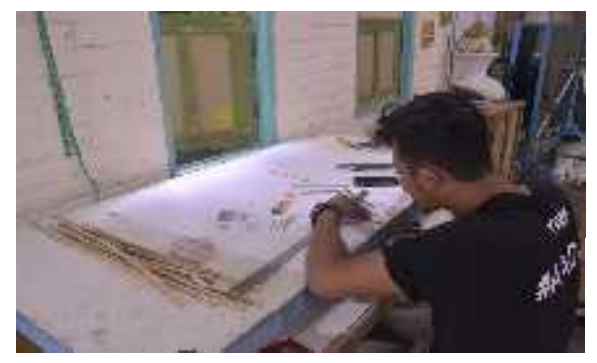

Gambar 1. Proses Kreatif Anggota PPT

(Foto: Dokumentasi Nugroho, 2017)

\section{Tour and Research}

Respons terhadap hal baru diimplementasikan secara kolektif melalui program tour and research, dan secara individu dilakukan menggunakan studi literasi (video, audio, buku, majalah, dan komik). Pernyataan ini diungkapkan pada kutipan wawancara di bawah ini.

...Sebenarnya saat tahun 2017 ini adalah saat yang paling cepat, karena di tahun ini 'kan lagi cooling downnya Papermoon, harapannya temen-temen bisa explore "kamu tertarik apa ya sana belajarlah gitu. Ini saatnya kita ngisi pundi-pundi pengetahuan kita lagi gitu...

(Wawancara Sulistyani, 13 April 2017)

Kutipan wawancara tersebut menunjukkan bahwa PPT selalu berproses, walaupun pada masa cooling down, di mana ada masa yang tidak banyak proyek yang harus dikerjakan. Proses yang dilakukan adalah mempelajari hal yang baru, baik secara kolektif maupun individu. Berkunjung ke tempat-tempat seperti studio (pertunjukan, seni rupa, film, dan radio), tempat produksi produk-produk budaya lain (batik, kain tenun, dan sejenisnya) menjadi keharusan, karena secara langsung memberikan tambahan pengetahuan yang dapat menjadi referensi ide pada proses produksi karya PPT selanjutnya.

Seperti yang diungkapkan oleh Jati (dalam wawancara 13 April 2017) yang menyatakan bahwa ketika ada kolaborasi dengan Perani (seniman Singapura), PPT harus melakukan penelitian untuk mempelajari kisah-kisah laut di Desa Lasem, dan sampai nanggep Wayang Bengkong sebagai objek riset. Melalui kolaborasi tersebut, PPT secara langsung menginvestasi pengetahuan yang digunakan saat karya itu diproses dan dalam proses-proses penciptaan karya selanjutnya.

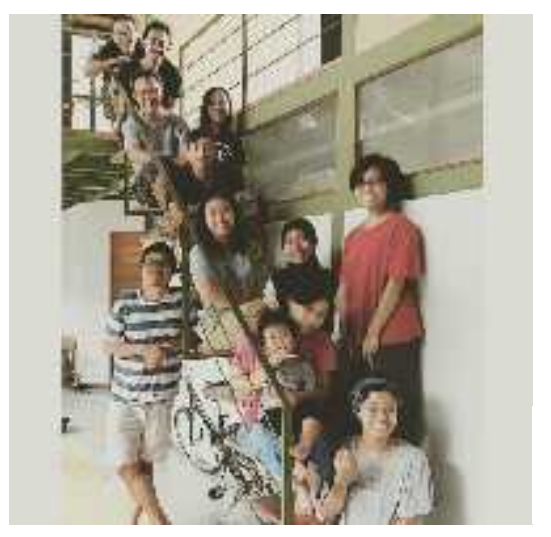

Gambar 2. Kunjungan di studio Radiomagno Magelang (Foto: Dokumentasi Papermoon, 2017) 
Kesempatan residensi dan pentas di beberapa negara tanpa keikutsertaan direktur dan artistik direktur, baik disengaja maupun tidak disengaja, sering dilimpahkan kepada anggota. Khusus untuk residensi, pihak PPT sering memberikan kesempatan bagi anggota untuk terlibat, walaupun biasanya residensi diikuti oleh direktur, dan/atau artistik direktur. Seperti pada pernyataan wawancara yang dikutip di bawah ini.

...waktu ke Thailand itu tahun 2014, kalau gak salah. Nah itu aku tawarin Griwo sama Beni "kalian mau gak nyoba recidency? Kan belum pernah selama ini, sendiri tapi gak ada aku gak ada Iwan? Ya mereka mau, ya udah kita cariin dana, kita cariin uang untuk mereka ke Thailand, recidency di ada satu link temen-temen yang punya art space kita kirim mereka ke sana...

(Wawancara Sulistyani, 13 April 2017)

Pada titik tertentu, Direktur PPT tidak mau seperti induk yang terus-menerus mengerami telurnya. Angota PPT tidak bisa pintar terbang kalau terus dierami. Di titik lain, PPT harus memikirkan strategi agar mampu membuat setiap anggota bisa terbang menunjukkan kualitas keterampilan yang dimiliki. Salah satu strategi yang dilakukan PPT adalah memberikan alternatif kesempatan yang lain bagi stakeholder internal PPT dalam menemukan relasinya. Pernyataan serupa diungkapkan oleh para anggota PPT dalam menyikapi strategi tersebut. Berikut ini kutipan wawancaranya.

...Eee.. Ketika bekerja di Papermoon dan kami banyak mengunjungi tempat-tempat baru gitu kok lama-lama muncul alternatif-alternatif. Misalnya terus itu tadi aku dapat peluang ketemu produser, produser baru, aku punya peluang untuk ketemu technical-technical direktur baru yang itu membuka kemungkinan kita untuk bekerja dengan mereka. Jadi, bahwa kemudian soal jenjang karir di dunia pertunjukan itu jadi semakin melebar gitu...

(Wawancara Paksi, 23 April 2017)

Pengalaman dan kesempatan itulah yang diperoleh anggota PPT, termasuk Paksi (technical director). Menurutnya, motivasi dan pengetahuan itu menjadi wujud apresiasi yang paling penting di dalam kerjanya sebagai seniman. Pentas keliling dan berhubungan dengan seniman teater boneka lainnya adalah strategi membangung jaringan. Menurut Sulistiyani (dalam wawancara 13 April 2017, di Rumah Papermoon) hal-hal seperti itu adalah bentuk investasi jangka panjang yang lebih luas, karena hubungannya dengan relasi yang membuka proyeksi tentang hidup. Kegiatan itu juga dijadikan refleksi untuk menentukan arah PPT, karena teater boneka itu tidak hanya di studio PPT saja, tetapi teater boneka memiliki jangkauan luas dan banyak referensi di luar daerah atau di luar negeri.

\section{Kolaborasi dan Residensi}

Kegiatan lain yang dapat menghadirkan pengetahuan baru bagi PPT adalah kolaborasi antar-seniman. Seperti dinyatakan oleh Efendi, bahwa:

...tiga tahun terakhir ini jadwal kita 'kan cukup padat, kita gak mungkin

belajar hal baru, jadi peluang yang kita buka itu adalah peluang kolaborasi, 
karena dengan kolaborasi, mau gak mau kita produksi, bekerja dapat duit sambil belajar...

(Wawancara Efendi, 30 Maret 2017)

Kolaborasi hadir sebagai tawaran untuk menjalin hubungan pertemanan, hubungan kerja, dan hubungan timbal balik untuk sama-sama mempelajari perilaku kreatif yang dilakukan oleh masing-masing kelompok seni. Hubungan timbal balik tersebut pula yang menginisiasi banyak seniman luar negeri seperti Lemony's Puppet Theater (AU), Babymime (Thailand), Kona Ote (Jepang), Tim Spooner (UK), Khadija Van Zinnenberg Caroll (Belanda), Anino Shadowplay Collective (Philifina), Wayang Sampah (Indonesia), dan masih banyak seniman-seniman lain yang pernah terlibat di Pesta Boneka menggunakan biaya sendiri. Jika dihitung finansial yang dibutuhkan untuk mendatangkan artis-artis tersebut maka, PPT belum mampu melakukannya. Akan tetapi kenyataannya berbanding terbalik, PPT mampu menghadirkan seniman mancanegara dengan mengandalkan modal "komunikasi" yang baik dan adanya kesadaran dari setiap seniman yang diundang.

Ketika pentas keliling di beberapa negara, komunikasi dijalin secara berkelanjutan. Mereka menyosialisasikan keberadaan Pesta Boneka dan menawarkan pengalaman interaksi dengan warga dan penonton yang apresiatif. Sulistyani menekankan bahwa kejujuran itulah mampu meyakinkan seniman-seniman bersedia terlibat (wawancara, 13 April 2017 di Rumah Papermoon).
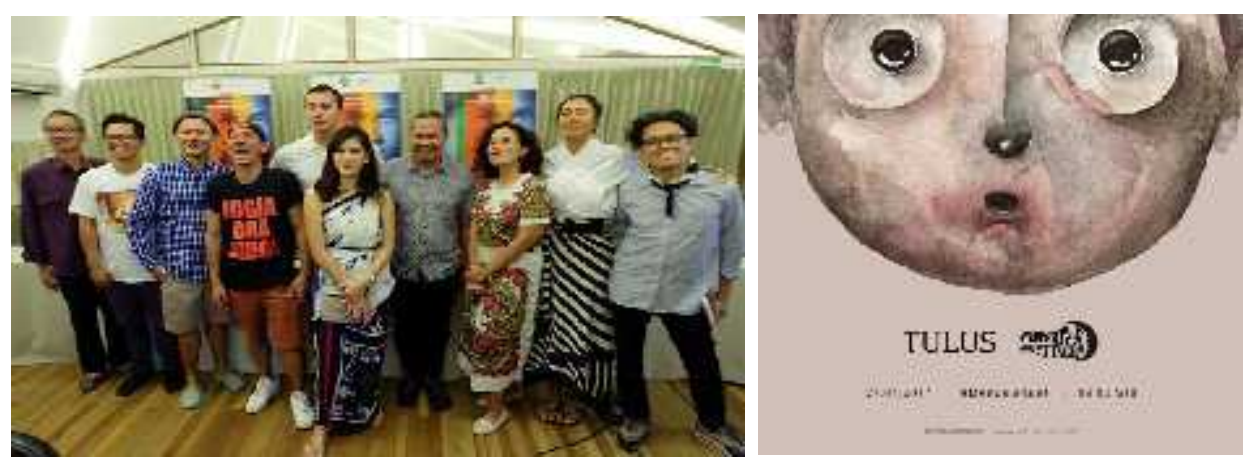

Gambar 3. Kolaborasi PPT dengan AADC dan Tulus (Foto: Dokumentasi PPT, 2015)

Investasi di dalam PPT tidak hanya dilakukan oleh seniman dan anggota PPT, tetapi juga datang dari pihak penonton yang secara sukarela membeli tiket bahkan menjadi donatur. Hal itu terjadi ketika penonton sudah percaya dengan PPT, bahkan ada penonton yang merasa ikut memiliki PPT (disebutkan pada sub-bab Peningkatan stakeholder Baru).

\section{Komunikasi melalui Dokumentasi}

PPT menyadari bahwa penonton mengharapkan informasi-informasi yang dapat meyakinkannya untuk datang menonton bahkan sampai memberikan donasi. Melalui dokumentasi itu, pengetahuan tentang PPT dibagikan kepada publik. Karena menurut 
Sulistyani, "kita tidak tahu apa yang akan terjadi di masa akan datang. Sebenarnya dokumentasi semacam ini tidak sepenuhnya berkualitas baik, akan tetapi, tindakan ini sudah kami lakukan dari awal." Dalam konteks penyebaran informasi ini, sosial media diberdayakan untuk menebar gaung dan merawat audiens. Karena menurut Sulistyani, "akan sulit jika harus memenuhi kunjungan tiap hari, tapi kalau kita ngebalas email dengan cara yang baik, minta maaf ya gak bisa gini, gini, gini" mereka juga gak ngerasa ditolak" (Wawancara Sulistyani, 13 April 2017).

Dari sudut pandang stakeholder internal berpandangan, bahwa PPT selalu membagi dan memperbaharui konten dalam akun media sosialnya (blog, Instagram). Perilaku ini dipandang positif oleh Gone yang berpendapat, bahwa:

... 'Kan orang bisa dapat informasi dari media sosial itu penting, karena setelah aku ngasi tau ke temen-temenku tentang Papermoon itu mereka langsung cek akun medsos Papermoon...

(Wawancara Gone, 5 April 2017)

Kutipan tersebut menunjukkan peran penting dokumentasi dalam rangka merawat dan membaca situasi perkembangan stakeholder (penonton) dan meyakinkan stakeholder untuk datang lagi dan bahkan berdonasi. Terbatasnya waktu bagi PPT untuk berkomunikasi dengan penonton ditutupi dengan pemberdayaan dokumentasi. Pada era digital dewasa ini, sosial media sudah menjadi gaya hidup. Bahkan hampir sejajar dengan kebutuhan primer, sehingga setiap orang tidak bisa terlepas dari keberadaan sosial media.

PPT berkewajiban selalu memberikan informasi-informasi kepada stakeholder terkait kegiatan PPT. Siklus ini dapat dilihat pada sub-bab sebelumnya bahwa PPT secara sistematis telah membangun jaringan komunikasi melalui kepercayaan stakeholder yang berdampak pada investasi stakeholder. Model investasi stakeholder PPT dapat dilihat pada diagram di bawah 1 .

Diagram 1. Model Investasi Stakeholder PPT

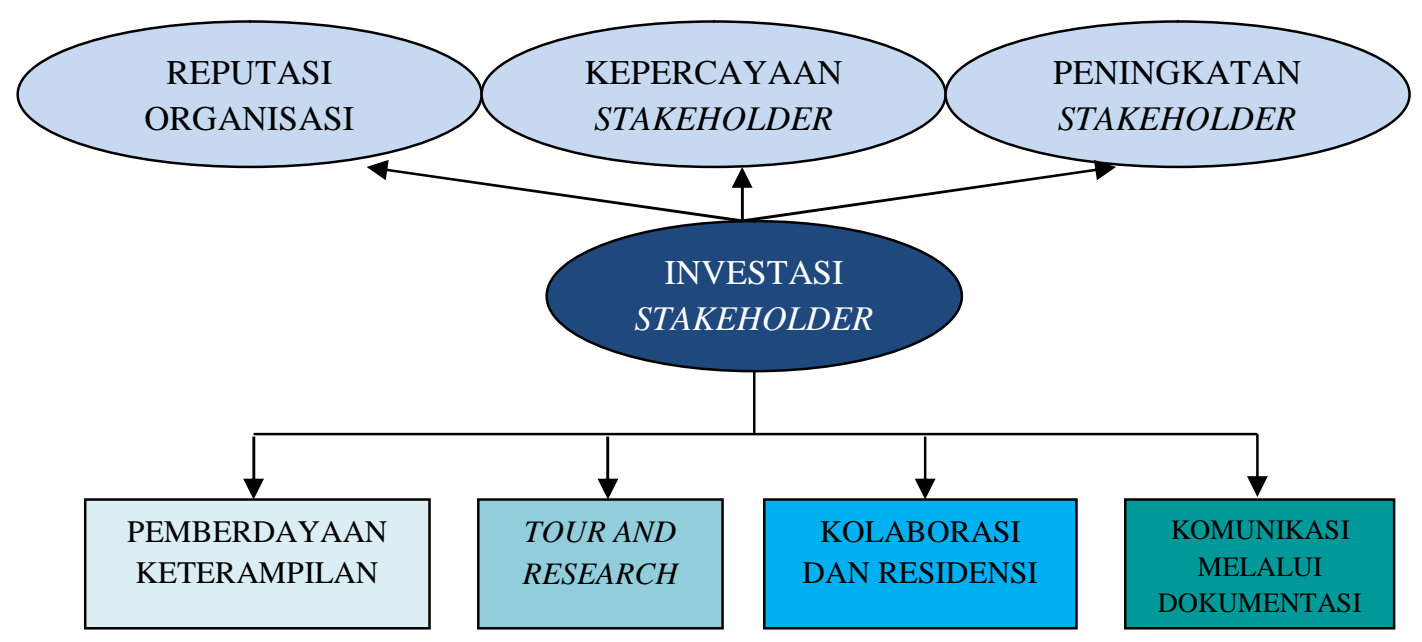




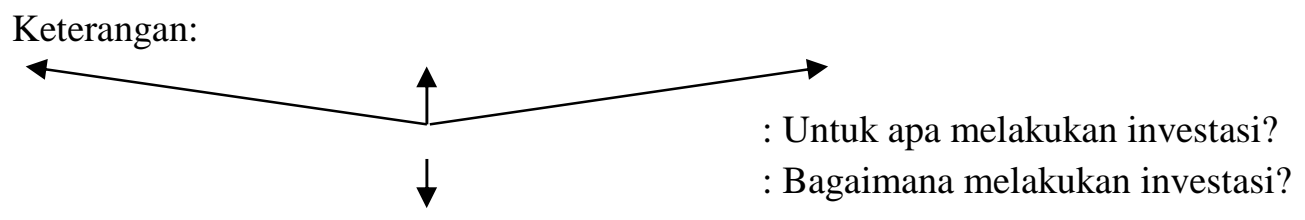

Penjelasan:

1. Muara dari pengelolaan Organisasi Seni Pertunjukan adalah Investasi, dalam konteks kehadirannya memelihara reputasi dan kepercayaan stakeholder yang sudah diraih. Di sisi lain, melalui investasi organisasi, mampu menjaga irama peningkatan jumlah stakeholder baru.

2. Investasi dapat dilakukan melalui pemberdayaan keterampilan sumber daya manusia di internal PPT, melakukan tour and research, kolaborasi, dan residensi guna memperoleh referensi baru, serta merawat audiens dengan memberdayakan dokumentasi media sosial.

\section{KESIMPULAN} yaitu:

Dapat disimpulkan bahwa investasi yang dilakukan oleh PPT, mencakup dua hal,

\section{Investasi stakeholder internal}

Melalui pemberdayaan keterampilan, setiap stakeholder memiliki kesempatan yang sama untuk berkreativitas (membuat boneka, cerita, dan kolaborasi). Kesempatan ini tentu berdampak pada aspek integritas seseorang pada suatu organisasi yang diikuti. Tour and research memberikan penyegaran terhadap pengetahuan dan ide setiap individu. Sedangkan kolaborasi dan residensi menjadi wadah penuangan dan penggalian kreativitas baru bagi para pesertanya.

2. Investasi stakeholder eksternal

Berkunjung ke studio-studio seniman, baik di dalam dan luar negeri, serta aktif memberdayakan media social, membuat PPT kaya dengan informasi dan wawasan, sehingga memudahkan mereka untuk berkomunikasi.

Semua bentuk pengembangan dan pemberdayaan yang dilakukan oleh PPT tersebut, diupayakan guna mendukung eksistensinya di dunia seni pertunjukan. Di sisi lain perlu dicermati bahwa PPT sudah memulai strategi untuk membentuk kemandirian setiap stakeholder internal, sebagai upaya agar tidak ketergantungan pada satu figur.

\section{KEPUSTAKAAN}

Coslor, Erica. 2009. Art Investiment Colections: A New Model for Museum Finance? Departement of Sociology 1126 East $59^{\text {th }}$ Street Chicago, IL 60637.

Mei, Jiangping, dan Moses, Michael. 2002. Art as an Invesment and the Underperfomance of Masterfaces. JEL G11, G12, Z10.

Papula, Jan dan Volna Jana. 2011. Intellectual Capital as Value Adding Element In Knowledge Management. Journal Managemen, Knowledge dan Learning. Page 497-504.

Tandelin, Eduardur. 2010. Portofolio dan Investasi. Yogyakarta: Kanisius. 
I Putu Ardiyasa, Investasi Stakeholder Organisasi Seni Pertunjukan...

Ulum, Ihyaul. 2009. Intellectual Capital: Konsep dan Kajian Empiris. Yogyakarta: Graha Ilmu.

Zagreb, 2007. Intellectual Capital: Handbook of IC Managemen in Companies. Kroasia: Mesnika.

\section{Webtografi}

Papermoon Puppet Theatre. (15 Februari 2017) kunjungan ke Studio Radiomagno Magelang. https://www.instagram.com/papermoonpuppet/ 4 Mei 2017

Papermoon Puppet theatre. (14 Juni 2017) The Tranlucence: on Progress. http://www.papermoonpuppet.com/ 22 Juni 2017.

abm. (11 Mei 2016) Lokasi Syuting Film AADC\#2 Jadi Buruan Penonton yang kepo. http://jogja.tribunnews.com/2016/05/11/lokasi-syuting-film-aadc-2-jadi-buruanpenonton-yang-kepo 4 Mei 2017.

Radio Nak Bali. (11 Januari 2012) Wayang Banglli Kang ing Wei http://radionakbali.blogspot.co.id/2012/01/wayang-bangli-kang-ching-wie.html/ 12 Oktober 2017

\section{Daftar Narasumber}

Maria Tri Sulistyani, Sutradara Teater PPT, wawancara langsung tanggal 13 April 2017 di Studio Papermoon, Bangun Jiwo, Kasihan Bantul.

Iwan Efendi, Perupa, Artistik Direktur PPT, wawancara langsung tanggal 31 Maret 2017, di Kediamannya, jalan Langen Suryo, Panembahan Keraton, Yogyakarta.

Gading Paksi, Direktur Artistik, wawancara langsung, tanggal 23 April 2017 di Prada Coffe, Yogyakarta.

Giasinta Anggone, Blogger dan penonton PPT. wawancara langsung tanggal 5 Mei 2017 di Millas Coffe, Yogyakarta.

Pambo Priyo Jati, wawancara langsung tanggal 13 April 2017 di Studio Papermoon, Bangun Jiwo, Kasihan Bantul. 